In: Franziska Sick (Hg.), Raum und Objekt im Werk von Samuel Beckett, Bielefeld: transcript, 2011, S. 27-53

\title{
Raumspiel und Raumregie im Endspiel und im Spätwerk Becketts
}

FRANZISKA SICK

\section{Vorüberlegungen}

Zu Beginn des Endspiels öffnet Clov auf der Bühne die Vorhänge vor den Fenstern, um möglichst umständlich erst aus dem einen und dann aus dem anderen $z u$ sehen. Nachgerade programmatisch setzt das Endspiel mit einem Raumspiel ein, so als ginge es darum, in einem pantomimischen Vorspiel auf dem Theater den Gehalt des Stückes vorwegzunehmen. Denn kaum mehr ereignet sich im Folgenden, als dass man - sich drinnen möglichst umständlich bewegend - auf einen leeren, nur schwer einsehbaren Außenraum zuspricht. Das Außen ist hierbei nicht nur der Raum außerhalb des Bunkers, sondern ebenso sehr die Küche, in der Clov kaum mehr zu tun hat, als die leere Wand zu betrachten, um dort sein Licht verlöschen zu sehen. ${ }^{1}$ Das Außen, das sind auch die Mülltonnen, in denen Nagg und Nell stecken. So wie Clov auf die Leiter steigt, um nachzusehen, ob draußen noch etwas geschieht, so hebt er mit selbem Interesse die Deckel der Mülltonnen an. Zu einem Außenraum in diesem Sinne gerät Clov selbst der Intimraum der eigenen Hose. Als er eine Filzlaus jagt, ist er, aber auch Hamm, mit der Frage befasst, ob dort in diesem Draußen-Drinnen sich noch etwas ereignet, sei es nun das Krabbeln der Laus oder das Pipimachen von Hamm. ${ }^{2}$

Man zitiert verbreiteter Weise aus dem Endspiel nicht die Clov'sche Hosenszene, sondern den Passus, der ihr vorangeht: "Hamm: Wir sind doch nicht im Begriff, etwas $\mathrm{zu}$... zu ... bedeuten? [...] Wenn ein vernunftbegabtes Wesen auf die Erde zurückkehrte

1 Vgl. Beckett, Samuel: Endspiel, in: ders., Dramatische Dichtungen in drei Sprachen. Französische und englische Originalfassungen, deutsche Übertragung von Erika und Elmar Tophoven. Ausgabe in einem Band, Frankfurt am Main: Suhrkamp 1981, S. 207-317, hier S. 223.

2 Vgl. ebd., S. 249-251. 
und uns lange genug beobachtete, würde es sich dann nicht Gedanken über uns machen? ${ }^{3}$

Gemessen an der Hosenszene formuliert Hamm an dieser Stelle ein vergleichsweise rückständiges und schwaches Argument. So wie bereits in Warten auf Godot wird für ihn Sinn und Bedeutung in dem Maße hinterfragbar, wie ein externer, transzendenter Beobachter ausständig ist. Die Hosenszene - und in der Grundanlage das Endspiel in toto - setzt solcher Dekonstruktion von Metaphysik und Bedeutung ein positiveres, da am Raum orientiertes Konzept entgegen: Während Wladimir und Estragon noch auf Godot warten, geht Clov, die Filzlaus jagend, dazu über, den Raum zu untersuchen.

Um diese Differenz kurz zu erläutern: Anders als das Endspiel bewegt sich Warten auf Godot noch im Umfeld des absurden und das heißt zugleich: des antimetaphysischen Theaters. Es konterkariert traditionelle Sinn- und Erlösungserwartungen, indem es die hoffnungsvolle Erwartung mit dem vergeblichen Warten konfrontiert. Da unbestimmbar bleibt, wer hinter Godot sich verbirgt - ein Gott, ein Financier oder auch eine Utopie -, tritt die Topologie solcher Sinnkonstruktionen hervor: Godot, dieses quid pro quo, ist die Struktur des ausständigen externen Beobachters, mit Berufung auf den man gängiger Weise Sinn zu konstituieren versucht. Selbst Heideggers Konzept des Vorlaufens zum Tode ${ }^{4}$ und, hieran anschließend, der französische Existenzialismus folgt, wenn auch in Abwandlungen, noch solcher Topologie des Sinns. Auch wenn im Vorlaufen zum Tode Dasein sich selbst begegnet, kann es Sinn von Sein nur gewinnen, indem es sich selbst als externen, da zukünftigen Beobachter setzt. Kaum anders operiert der Heidegger von Sein und Zeit an dieser Stelle als traditionelle Religionen. Er ersetzt lediglich den externen Betrachtergott durch einen externen 'Selbstgottı.

Obwohl oder aber auch weil Warten auf Godot solche Religion und Philosophie konterkariert, ist es in noch vergleichsweise hohem Maße traditioneller Metaphysik verhaftet. Auch wenn Godot nicht kommt, macht das Warten auf ihn den Lebensinhalt von Wladimir und Estragon aus. Obwohl das Stück in ersten Ansätzen topologische, räumliche Strukturen ins Spiel bringt, ist in ihm das Thema der Zeit noch zentral gesetzt. Das klingt bereits im Titel an und schreibt sich in den Zentralmotiven der Handlung fort. Wartender Weise schlagen Wladimir und Estragon die Zeit tot. Vergesslicher Weise entfällt Estragon nur allzu oft, worauf er denn wartet. Aufgrund dieser Präponderanz von Zeit - und nicht, weil Godot mit

3 Ebd., S. 249.

4 Vgl. Heidegger, Martin: Sein und Zeit, Tübingen: Niemeyer ${ }^{14} 1977$, S. $301-$ 331. 
einem ausständigen Gott gleichzusetzen wäre - ist Warten auf Godot im Umkreis des absurden und antimetaphysischen Theaters zu verorten.

Ungleich vorweisender ist demgegenüber die Grundanlage des Endspiels. Während Warten auf Godot die sinntragende Zeit anhält, um Sinn zu blockieren, wechselt das Endspiel das Paradigma: Es ersetzt die Zeit durch den Raum, es ersetzt das Warten durch die Inspektion eines leeren, ereignislosen Raums. Mit dieser Wende positioniert sich das Endspiel jenseits des Bezugsrahmens von Sinn und Absurdität. Sinn gibt es nur in Beziehung zur Zeit, nicht jedoch in Beziehung zum Raum. ${ }^{5}$ Räume erfordern andere, eigenständigere Zugangsweisen als die des Sinns. Man kann Räume inspizieren oder aber auch - wie im Titel Endspiel bereits anklingt - in ihnen Züge machen. Eine der zentralen Pointen des Endspiels und der in ihm anklingenden Schachmetapher ${ }^{6}$ besteht darin, dass Beckett dieses komplexe Strategiespiel auf eine Standard-, wenn nicht gar auf eine Pattsituation, auf ein finales isinnloses ' Hin- und Herziehen reduziert. ${ }^{7}$ Alle späteren Raumspiele Becketts sind hiervon geprägt: Sie führen komplexe Lebenssituationen, die Beckett als Raumspiel auffasst, auf einfache iterative Spielbewegungen zurück.

\section{Raumregie}

Aufgrund der ihm eigenen Räumlichkeit ist das Endspiel in erheblichem Umfang nicht länger gesprochenes, sondern besprochenes, regiehaftes Drama. Das zeigt sich in der Eingangsszene, die in aller Präzision den Ablauf der Pantomime festlegt. Aber auch der weitere Text ist vielfach von solchen Regieanweisungen durchsetzt. "Er geht zur Tür und bleibt stehen." "Clov bückt sich [...]. Clov richtet sich wieder auf." ${ }^{9}$ Selbstredend finden sich solche Regieanweisungen auch in traditionellen Theaterstücken. Sie häufen sich jedoch bei Beckett. Besprochen werden Raum und Regie im Endspiel nicht nur in Form der Regieanweisung. Als Raum besprechende und im Raum

5 Man kann dem mit Heidegger widersprechen: Auch Plätze und ihre Einbettung in eine Bewandtnisganzheit implizieren augenscheinlich Sinn. Und man muss zugleich diesen Einspruch zurücknehmen: Solche sinnhaften Plätze sind in der Sorge fundiert und diese ist nicht ohne Zeit zu denken.

6 Vgl. hierzu Kenner, Hugh: Samuel Beckett. Eine kritische Studie, München: Hanser 1965, S. $146 f$.

7 Man diskutiert diesen Punkt in der Forschung bekanntlich kontrovers. Die vielleicht naheliegende Frage, wer das Endspiel denn nun gewonnen hat, erscheint mir jedoch zu konkretistisch.

8 S. Beckett: Endspiel (wie Anm. 1), S. 225; ähnlich ebd., S. 239.

9 Ebd., S. 269, 291. 
Regie führende Akteure erweisen sich ebenso sehr die Figuren des Stücks. Teilweise zeichnet sich dies explizit in einer Reflexion auf die eigene Figurenhaftigkeit ab. Wendungen wie "Also, ich bin dran. Pause. Jetzt spiele ich " ${ }^{10}$ stehen hierfür ein. Teilweise ist solche Raumregie in die Handlung integriert. So etwa, wenn Hamm Clov pfeift, wenn dieser sagt: "Ich gehe jetzt", oder wenn Hamm Clov anweist, ihn genau in die Mitte des Zimmers zu schieben. ${ }^{11}$

Zum Schluss des Stücks kippt die besprochene Regie in ein selbstauferlegtes Schweigegebot um: "... kein Wort mehr", sagt Hamm. Das allerletzte Wort, das er dann doch noch sagen muss, verweist auf den Theaterraum: "Altes Linnen! Pause. Dich behalte ich." ${ }^{12}$ Damit schließt das Stück, wie es begonnen hat: Es eröffnet mit einem ereignislosen Raum ohne Worte und schließt mit einem Einspruch gegen das Wort. Wie in einer Rahmenhandlung ist in der Eingangs- und Schlussszene gesetzt, dass das Endspiel ein Raumspiel, ein Spiel sich öffnender und schließender, aber auch verschlossener und unzugänglicher Räume ist. Wie sehr hierbei das gesprochene Wort hinter dem Raumspiel zurücksteht, obwohl die ganze Handlung des Stückes darin besteht, im Raum sprechender Weise Regie zu führen und den Raum zu besprechen, zeigt die Schlussszene: Obwohl Clov ankündigt, Hamm zu verlassen, bleibt er bis zum Schluss stehen.

In der Berliner Inszenierung ${ }^{13}$ hat Beckett, selbst Regie führend, den Widerspruch der Schlussszene, diesen Widerspruch von gesprochenem Wort und besprochener Regie - Die Figur sagt: "Ich gehe", der Regisseur sagt: "Du bleibst auf der Bühne" - versucht, selbst noch in den Zuschauerraum hineinzutragen. Eines seiner größten Anliegen war, dass das bühnentechnische Ende des Endspiels nicht länger gängiger Applausordnung unterworfen wird. Beckett setzte diesem fragwürdigen Ereignisraum den statischen des Endspiels entgegen. Er hat darauf bestanden, dass, auch wenn man hinten klatscht, vorne sich niemand verbeugt. Das letzte Bild das ist das Bild Clovs, der nicht abgehen kann - sollte beim Applaus wie eingefroren als Tableau stehen bleiben und lediglich mehrfach angeleuchtet und verdunkelt werden. Damit streicht Beckett in der Berliner Inszenierung aus dem Endspiel noch das letzte Moment von Ereignishaftigkeit: das der Aufführung. Der Raum des Endspiels ist kein Theaterereignis. Er bleibt stehen, weil

10 Ebd., S. 313.

11 Vgl. ebd., S. 241.

12 Ebd., S. 317.

13 Vgl. Haerdter, Michael: "Samuel Beckett inszeniert das Endspiel. Bericht von den Proben der Berliner Inszenierung 1967«, in: Materialien zu Becketts »Endspiel«. Berichte und Aufsätze, Frankfurt am Main: Suhrkamp ${ }^{2} 1970$, S. 36-137. 
obstinate Räumlichkeit durch kein Ereignis zu umklammern und zu relativieren ist, auch nicht durch das Theaterereignis, auch nicht durch die Klammer der Fiktion. In der Berliner Inszenierung sehen wir späten Beckett, der frühen Beckett inszeniert. Es wird zu zeigen sein, dass der späte Beckett nicht nur in der Berliner Inszenierung den Außenraum in den Zuschauerraum hinausstülpt.

\section{Bespielter Raum}

Der Akzent auf Räumlichkeit prägt im Endspiel nicht nur die Raumregie, sondern darüber hinaus wesentliche Handlungsmomente und Motive des Stücks: Das Endspiel thematisiert viermalig eine Mauerschau, des Weiteren eine Reise durch den Bunker sowie ein Spiel von Da-Sein und Verlassen. Man kann aufgrund dieser Grundanlage das Endspiel - mit Abstrichen ${ }^{14}$ - wie eine kleine Phänomenologie des Raumes lesen: Es entfaltet grundsätzliche Zugangsweisen zum Raum. Man kann Räume inspizieren. Man kann sie bereisen. In Räumen sind nicht zuletzt Mitmenschen vorfindlich.

Diese Zugangsweisen spiegeln sich einigermaßen unmittelbar in den Requisiten des Stücks: Es ist ausgestattet mit Inspektionswerkzeugen wie dem Fernrohr und der Leiter, mit Reisewerkzeugen wie dem Sessel und dem Bootshaken, und nicht zuletzt mit Dingen, die Präsenz und Absenz des Anderen regeln, wie die Trillerpfeife, die Deckel der Mülltonnen und der Wecker. Kaum weniger streng tragen sich diese drei Zugangsweisen auf der Grobgliederung des Bühnenraums ab: Der Außenraum und die Fenster verweisen auf das Thema der Inspektion, Hamms Zimmer auf das der Reise, Clovs Küche und die Mülltonnen auf das der Vorfindlichkeit des Anderen im Raum.

Selbst der Charakter der Figuren ist von solchen Modalitäten der Raumerschließung geprägt. Während Clov gehen und sehen kann, weil er für den Aspekt der Rauminspektion zuständig ist, kann Hamm beides nicht. Anders als Clov, der sich nicht setzen kann, kann Hamm nur dies: "Jedem seine Spezialität." ${ }^{15}$ Obwohl Hamms Bewegungsmöglichkeiten äußerst eingeschränkt sind, hat auch Hamm einen durchaus eigenen, positiven Zug- und Spielwert. Hamm ist der Reisende. Wie zumal der moderne Reisende besitzt er einen fahrbaren Untersatz. Nicht zuletzt sind selbst Nagg und Nell,

$14 \mathrm{Zu}$ unterscheiden von einer Phänomenologie im strikten Sinn ist die Beckett'sche >Raum-Phänomenologie<, weil Beckett keine Phänomeno-Logie machen will. Passender erscheint mir der Begriff des Raumspiels. Bei Raumspielen ist die Logik der Phänomenologie gleichsam im Raum inkorporiert.

15 S. Beckett: Endspiel (wie Anm. 1), S. 221. 
die in ihren Tonnen gefangen nahezu zur Bewegungslosigkeit verurteilt sind, mit einem eigenen Bewegungsprofil ausgestattet: Sie ziehen sich mit den Händen aus der Tonne.

Durchweg sind die Figuren des Endspiels durch ihren Zugwert bestimmt. Sie sind deshalb nur noch in eingeschränktem Maße dramatische Figuren, ${ }^{16}$ sie haben kaum noch einen eigenen Charakter, sondern nur noch einen Spielwert im Raum - so wie etwa die Figuren im Schach. Mit anderen Worten: Sie sind zu großen Teilen nicht dramatische, sondern ludische Figuren. Ludische Figuren sind durch ihre Bewegungsmöglichkeiten im Raum, aber auch durch weitere Eigenschaften wie Kampf- oder Inspektionswert charakterisiert. ${ }^{17}$ Der Umstand, dass Clov sehen kann und Hamm nicht, ist in diesen Kontext zu stellen. Abzuweisen ist an dieser Stelle das vielleicht naheliegende Missverständnis, ludische Figuren seien ausschließlich über ihren Zugwert charakterisiert. Der Zug, die Bewegung im Raum, ist nur ein Modus von Raumerschließung unter anderen. Zu kurz greifen deshalb Interpretationen, die das Endspiel auf ein rein räumlich-choreographisches Bewegungsspiel zu reduzieren versuchen. Die Figuren des Endspiels besitzen ein Sehfeld, Bewegungsattribute wie den Bootshaken, die Reichweite eines Tast- und Kratzfeldes bei Nagg und Nell. Und selbst wenn sie - am Gegenpol solch handfester Raumerschließung - bloß miteinander diskutieren, sind die Auseinandersetzungen zwischen ihnen von einer gewissen Zughaftigkeit geprägt: Immer wieder verstellen Clov und Hamm einander argumentativ den Weg. Sie beziehen Position ohne Argument, bloß um die Zugmöglichkeiten des Anderen zu blockieren.

Clov: Ihr wollt also alle, daß ich euch verlasse.

Hamm: Natürlich!

Clov: Dann werde ich euch verlassen.

16 Dramatische Figuren sind sie, insofern sie reden. Dass ihre Sprache, gemessen am traditionellen Drama, gleichwohl kaum mehr dramatisch zu nennen ist, hat schon früh Wolfgang Iser gezeigt; vgl. Iser, Wolfgang: "Samuel Becketts dramatische Sprache« (1961), in: Karl Alfred Blüher (Hg.), Modernes französisches Theater. Adamov - Beckett - lonesco, Darmstadt: Wissenschaftliche Buchgesellschaft 1982, S. 140-160, mit Bezug auf das Endspiel bes. S. 143-149.

17 So ist beispielsweise das Computerspiel Civilization mit Soldaten und Spähern ausgestattet. Erstere können Land erobern und verteidigen. Dabei besitzen sie einen je unterschiedlichen Kampfwert: Der römische Legionär ist schwächer als die moderne Artillerie. Letztere (die Späher) besitzen keinerlei Kampfwert. Sie können jedoch schneller ziehen als die Soldaten. Sie eignen sich deshalb dazu, den Raum zu erkunden, sie sind gewissermaßen die Brille des Spiels. 
Hamm: Du kannst uns nicht verlassen.

Clov: Dann werde ich euch nicht verlassen.

Pause

Hamm: Du brauchst uns nur zu erledigen. [...]

Clov: Ich könnte dich nicht erledigen.

Hamm: Dann wirst du mich nicht erledigen. ${ }^{18}$

Zumal in dem "dann [...] nicht", das man später in Georges Perecs L'Augmentation wiederfinden kann, ${ }^{19}$ klingt an, dass der Proponent ein argumentatives Feld besetzt, das der Opponent eben deshalb nicht mehr betreten kann. Deshalb argumentiert er an dieser Stelle nicht weiter, sondern geht zum nächsten Zug über. Ganz anders ist noch der Diskurs zwischen Wladimir und Estragon verfasst. Er kulminiert in einem wechselseitigen Zuspruch, der in ein abstruses, nachgerade lexikalisches Quodlibet umschlägt.

Estragon: $\quad$ Es ist schrecklich.

Wladimir: Wie im Theater.

Estragon: Im Zirkus.

Wladimir: Im Varieté.

Estragon: Im Zirkus. ${ }^{20}$

Man kann die Auffassung vertreten, beide Dialoge seien gleichermaßen absurd, wobei nicht zu übersehen ist, dass Wladimir und Estragon gemeinsam die Sprache entleeren, während Clov und Hamm sie dazu benutzen, um ihre argumentativen Spielchen und Züge zu inszenieren. Bis in die Ausgestaltung der Wechselrede zeigt sich, in wie hohem Maße Beckett das Drama, diese Gattung verbaler Auseinandersetzung, einsetzend mit dem Endspiel in ein Raumspiel überführt: Es geht nicht länger darum, ob man sich in Kommunikation Sinnvolles oder Sinnloses sagt, sondern nur noch darum, mit Sprache argumentative Räume zu besetzen. Nicht zu verwechseln ist diese raumbesetzende Sprache mit gängiger Sprechakttheorie, da sie das Sprachhandeln als Spezialfall von Raum-

18 S. Beckett: Endspiel (wie Anm. 1), S. 255.

19 Vgl. Perec, Georges: L'Augmentation, in: ders., Théâtre I, Paris: Hachette 1981, S. 9-59. Zur Interpretation des Stückes vgl. Sick, Franziska: »Konfigurationen von Drama, Spiel und Geschichte im postdramatischen Drama Frankreichs«, in: Achim Barsch/Helmut Scheuer/Georg-Michael Schulz (Hg.), Literatur-Kunst-Medien. Festschrift für Peter Seibert zum 60. Geburtstag, München: Meidenbauer 2008, S. 130-156, hier S. 133-139. In diesem Aufsatz wird auch der Begriff der ludischen Figur entwickelt, vgl. ebd., S. $153 \mathrm{f}$.

20 Beckett, Samuel: Warten auf Godot, in: ders., Dramatische Dichtungen in drei Sprachen (wie Anm. 1), S. 7-205, hier S. 69. Es gibt weitere Quodlibets in diesem Stück, wie z.B. die Leibesübungen; vgl. ebd., S. 161. 
handeln auffasst. Argumentative Züge sind nur ein Auswuchs von Raumbesetzungen, die viel fundamentaler und mächtiger sind als die Sprachspiele der Sprechakttheorie.

Obwohl bereits in Warten auf Godot erste Ansätze für ein ludisches Figurenkonzept zu verzeichnen sind, ${ }^{21}$ bildet dieses erst im Endspiel das Grundgerüst des Stückes. Auch wenn man für gewöhnlich Warten auf Godot und Endspiel unter der Kategorie des Ifrühen Beckettı zusammenspannt, ist nicht zu übersehen, dass das Endspiel aufgrund seines streng räumlich-ludischen Konzepts ungleich vorweisender auf die späteren Stücke Becketts ist. Man denke etwa an Quadrat. Hier wie dort bilden räumliche Zugmöglichkeiten die Grundkonstruktion des Stückes. ${ }^{22}$ Aus Warten auf Godot sind vergleichbare Projektionen auf das Spätwerk nicht ableitbar. Das hat, wie bereits angemerkt, grundsätzlich damit zu tun, dass Warten auf Godot noch ein Zeit-Stück und kein Raum-Stück ist. Es ist überdies - und dieser Aspekt deutet in dieselbe Richtung - noch mehr ein Ding-Spiel als ein Raum-Spiel: Im Kampf mit den Dingen, im Kampf mit dem Requisit schlagen Wladimir und Estragon in chaplinesker Weise die Zeit tot. So leer auch die Bühne bereits in Warten auf Godot ist, die Handlung des Stückes ist durchs HutAufsetzen, Schuhe-An-und-Ausziehen, Koffertragen und -absetzen skandiert. Komischen Ding-Spielen haftet, in welcher Form auch immer, das Moment der Entfremdung oder aber auch nur das des Sinnwidrigen an. Sie entfalten ihr Spannungsverhältnis daraus, dass sich das Ding dem erwarteten Zweck nicht fügt, dass es nicht passt - so wie die Schuhe oder der Hut -, oder dass man es, aus sozialem Kalkül, sinnwidrig handhabt: Lucky setzt den Koffer bloß deshalb nicht ab, weil er eine Kündigung vermeiden will. Das Endspiel streicht solche Dinge weitgehend. "Es gibt nicht mehr" ist eine der prägenden Parolen des Stücks: "Es gibt keine Fahrräder mehr", "es gibt keinen Brei mehr, nur Zwieback." ${ }^{23}$ Es gibt nicht einmal mehr Natur. Das einzige, was es noch gibt, sind in durchaus differenzierter und exuberanter Weise Raumdinge: ${ }^{24}$ Sessel mit Rädern, Fernrohre, Leitern, Vorhänge, Trillerpfeifen, Tonnendeckel.

21 Vgl. hierzu den Beitrag von Mark Nixon in diesem Band, der darlegt, wie genau Beckett bereits in Warten auf Godot die Bewegungsabläufe auf der Bühne kalkuliert.

22 Die Unterschiede sind nicht zu verschweigen. Das Endspiel legt die Zugmöglichkeiten der Figuren mit vergleichsweise konkreten attributiven Zuschreibungen fest: Die Figur ist blind, lahm usw. Abstrakter ist Quadrat aufgebaut. Die Zugmöglichkeit ergibt sich hier aus dem reinen Bewegungsspiel.

23 S. Beckett: Endspiel (wie Anm. 1), S. $219,221$.

24 Eine Ausnahme in dieser entdinglichten Welt bildet der Hund. Seine Leine, die noch nicht fertig ist, und der Knochen, um den er betteln soll, erinnern 
Adornos Versuch, das Endspiel zu verstehen scheitert, weil er solche Entdinglichung auf Verdinglichung bezieht ${ }^{25}$ und dabei übersieht, dass die verbleibenden Dinge bei Beckett vom Endspiel an auf Raumspiele bezogen sind. Es mag sein, dass Beckett im Endspiel den Existenzialisten ihren verquasten Begriff der Grenzsituation vorhält. Adorno zitiert Jaspers: "Tapferkeit ist in der Grenzsituation die Haltung zum Tode als unbestimmte Möglichkeit des Selbstseins. ${ }^{26}$ Trotz Adornos Invektiven ist nicht zu übersehen, dass seine eigene Position, Raum-Zeit-systematisch betrachtet, durchaus strukturverwandt mit derjenigen Jaspers' ist. Adorno setzt gegen das Zeitmodell des Seins zum Tode lediglich das ältere der Geschichtsphilosophie. Gemeinsam ist beiden Ansätzen, dass sie dem Raum ein Zeitkonstrukt inokulieren, um ihn so auf die Sinnfrage oder aber auch auf das Absurde beziehen zu können. Hierbei bleibt außer Acht, dass Becketts Figuren primär im Raum befangen sind. Zeit gibt es in diesen Räumen nur als Raumspielzeit. Diese ist nicht final, sondern iterativ. Deshalb kann und will dieses Spiel nicht enden.

Man kann die Gemeinsamkeit zwischen Adorno und den Existenzialisten auch vom Begriff der (Grenz-)Situation her, und das heißt: raumtheoretisch auflösen. Der Begriff Situation impliziert stets eine subjektive Situation. Man ist in eine Situation hineingeraten, der man sich stellen muss - das kann eine persönliche Grenzsituation oder aber auch eine historische Situation sein. So sehr auch Adorno in seinem Versuch, das Endspiel zu verstehen gegen den existenzialistischen Begriff der (Grenz-)Situation polemisiert, so wenig kommt er selbst ohne den Begriff der Situation aus. Er liest das Endspiel als postapokalyptisches Endzeitstück, und das heißt, er bezieht es auf eine historische Situation. Im Grunde haben wir es in der Kontroverse Sartre-Adorno mit einer Kontroverse von zwei Zeittheoretikern zu tun. Woran ist das Leben zu orientieren? Am eigenen Tod oder an einer wie auch immer verstellten Utopie? Stets ist hierbei Raum als situativer Zeit-Raum gedacht.

an Lucky in Warten auf Godot. Wie hier die Herr-Knecht-Beziehung zitiert der Hund im Endspiel eine Figur von Verdinglichung. Einen anderen Typus von Raumdingen stellt Horst Breuer unter dem Begriff der >Trostobjekte vor: Sie trösten über die Absenz des Anderen hinweg. Vgl. den Beitrag von Horst Breuer in diesem Band.

25 Vgl. Adorno, Theodor W.: »Versuch, das Endspiel zu verstehen«, in: ders., Noten zur Literatur (= Gesammelte Schriften 11), Frankfurt am Main: Suhrkamp 1974, S. 281-321, hier S. 293.

26 Jaspers, Karl: Philosophie, Bd. 2: Existenzerhellung, Berlin/Göttingen/ Heidelberg: Springer ${ }^{3} 1956$, S. 225, zit. nach Th. W. Adorno: »Versuch, das Endspiel zu verstehen« (wie Anm. 25), S. 295. 
Becketts Raummodell entzieht sich solchem philosophischen 'Situationismus'. Beckett versucht die Spielmuster im Raum offenzulegen. Diese erscheinen ihm grundlegender als die der Zeitlichkeit und der Situation. Auch wenn wir je und je in einer Situation befangen sind, auch wenn wir uns dieser Situation stellen müssen, stellt sich die Frage, ob wir nicht in einer viel grundsätzlicheren Weise im Raum befangen sind, und ob wir nicht aufgrund dieser Befangenheit im Raum von Situation zu Situation immer wieder dieselben Spiele spielen.

Eben deshalb stellt die Handlung des Endspiels den Raum ins Zentrum. Es thematisiert mit der Rauminspektion, mit der Reise sowie mit der Räumlichkeit des Mitmenschen grundlegende Formen von Raumerschließung. Ich werde diese drei Aspekte im Folgenden gesondert betrachten und beginne mit der Rauminspektion, und das heißt: mit der Mauerschau.

\section{Mauerschau}

Vielschichtig konterkariert die Mauerschau im Endspiel die des klassischen Dramas. Während sie dort dazu dient, Ereignisse zu referieren, die auf der Bühne nicht darstellbar sind, bespricht die Mauerschau des Endspiels einen ereignislosen Raum, in dem sich nichts bewegt. Dergestalt stülpt Beckett die Mauerschau, die ein dramentechnisches Hilfskonstrukt ist - sie zeigt das technisch oder aber aus Gründen der Sittlichkeit auf der Bühne nicht Darstellbare -, in ein Generalverdikt über das Drama um. Draußen geschieht so wenig wie drinnen. Der ereignislose Raum höhlt das Drama aus und ersetzt seine Ereignishaftigkeit durch die Statik eines jedem Ereignis vorausliegenden Raums: Das Land, das Meer, dazwischen der Bunker. Das ist wenn nicht die Situation, so doch die Lage, und um kaum mehr als um eine Lagebeschreibung, um eine Auslotung des Raums geht es im Endspiel.

Nicht einmal Zeitbezüge lassen sich aus diesem Raum ableiten. Ist es Abend? Clov schaut mit dem Fernrohr aus dem Fenster, um festzustellen, ob die Sonne scheint und wie spät es ist. Mit einem Raumwerkzeug versucht er die Zeit zu bestimmen. Wenig sieht er hierbei. Es ist grau oder hellschwarz. ${ }^{27}$ Und so bleibt aufgrund solcher Unzeit und Optik nichts weiter, als diesen zeitlosen Außenraum zu besprechen. Nicht länger - wie sonst in der Mauerschau verleiht der Außenraum dem Drama hierbei neue Impulse. Stattdessen besteht die Handlung des Endspiels darin, den Raum als solchen zu inspizieren. Szenisch deutlich wird diese Verschiebung

27 Vgl. S. Beckett: Endspiel (wie Anm. 1), S. 247. 
zumal in den Zurichtungen Clov'scher Mauerschau. Während der Blick nach draußen im traditionellen Drama kaum besonderer Vorkehrungen bedarf, stellt das Endspiel in slapstickhafter Manier heraus, dass man vor jeglicher Mauerschau erst einmal die Mauer besteigen muss. Reichhaltig entfaltet das Stück diesen Spiel- und Dingraum. Die Fenster sind zu hoch angebracht. Clov braucht deshalb eine Leiter und überdies ein Fernrohr. Er trägt die Leiter hin und her. Einmal verlegt er das Fernrohr. Ein anderes Mal legt er die Leiter ans falsche Fenster, und da er meerwärts und nicht landeinwärts schaut, vermutet er, das Land sei überschwemmt. Selbst als Clov draußen einen Knaben sieht, bleibt dieses Ereignis zumindest für Hamm ungewiss.

Einigermaßen präzise kollabiert an dieser Stelle das System endspielhafter Mauerschau. Das zeigt ansatzweise der streng kombinatorisch komponierte Verlauf der viermaligen Mauerschau. In der ersten und dritten sieht Clov auf eigenes Betreiben aus dem Fenster, in der zweiten und vierten auf Betreiben Hamms. In der ersten und zweiten ist draußen nichts Besonderes zu sehen, in der dritten und vierten ist das, was draußen zu sehen ist, fraglich. Während Clov sich in der dritten Mauerschau selbst korrigiert - er räumt ein, dass da draußen keine Flut ist -, zieht in der vierten der blinde Hamm Clovs Bericht in Frage und ersetzt ihn durch ein Kalkül. Ich zitiere den entscheidenden Passus:

Hamm: Wenn er [der Knabe] existiert, kommt er hierher oder er stirbt dort.

Und wenn er nicht existiert ... Laß nur.

Pause

Clov: $\quad$ Du glaubst mir nicht? Du glaubst, daß ich schwindele?

Pause

Hamm: $\quad$ Es ist zu Ende, Clov, wir sind am Ende. Ich brauche dich nicht mehr. Pause.

Clov: Das kommt gut aus.

Er geht zur Tür. ${ }^{28}$

Wenn man die Matrix der vier Mauerschauen aufzeichnet, zeigt sich die nachgerade katastrophische Grundstruktur des Endspiels. Sie besteht darin, dass das System der Mauerschau, dass der Versuch, das ereignislose Draußen zu besprechen, zusammenbricht. Nichts sieht Clov zu Beginn in einsamer Mauerschau und lacht, nicht länger glaubt ihm Hamm zum Schluss. In durchaus hintergründiger Weise schreibt Beckett einem Stück, in dem im Grunde nichts sich ereignet, eine streng abfallende dramatische Verlaufsform ein.

28 Ebd., S. 309. 
Dass die vierte Mauerschau katastrophischen Charakter besitzt, zeigt sich bereits daran, dass Hamm das Stichwort "Es ist zu Ende" ausgibt, aber auch daran, dass das Stück mit ihm in der Tat zu seinem Ende kommt. Kaum weniger deutlich stellt Beckett dar, was inhaltlich zu dieser Katastrophe führt. Das System der endspielhaften Mauerschau bricht genau dann und dort zusammen, wo Hamm Clov nicht mehr glaubt, und deshalb trotz seiner Blindheit und Bewegungsunfähigkeit seinerseits die Position des Mauerschauers reklamiert. Das ist ein unübersehbar skurriles Finale. Der Blinde und Lahme, der weder die Mauer besteigen noch das, was vor ihr stattfindet, sehen kann, versucht den Mauerschauer Clov zu beerben.

Beanspruchen kann Hamm diese Rolle, weil er den Raum in ein Raumkalkül auflöst. Diesen Grundzug im Beckett'schen Werk hat umfänglich Gilles Deleuze herausgearbeitet: Deleuze zufolge sind die Protagonisten Becketts erschöpft, weil sie in einem Möglichkeitsraum befangen sind, in dem alles, was möglich ist, bereits vorgegeben ist und - sofern man die Achse Möglichkeit-Verwirklichung betrachtet - deshalb nichts mehr möglich ist. ${ }^{29}$ Solche Erschöpfung zeichnet sich bereits ab, als Clov in seiner ersten Mauerschau diese mit einem verächtlichen Lachen quittiert. Dabei ist nicht zu übersehen, dass bei aller Statik des Möglichkeitsraums zumindest das Endspiel noch eine gewisse dramatische Verlaufsform besitzt. Obwohl Clovs verächtliches Lachen bereits alles vorwegnimmt, steht im Hauptteil des Stücks dieser ereignislose Möglichkeitsraum immerhin noch zur Diskussion. Dieses Spiel ist zu Ende, wenn der blinde Hamm dazu übergeht, den sehbaren Raum in ein reines Kalkül, und das heißt: in einen reinen Möglichkeitsraum zu überführen. Da er die Regel des Spiels, wie implizit auch immer, auf den Punkt bringt, da er jegliches Ereignis auf einen Möglichkeitsraum bezieht, benötigt er Clov nicht länger.

\section{Hamms kleine Reise}

So prägend die Mauerschau für das Endspiel ist, so wenig ist ein weiteres Handlungsmoment auszublenden: Weil draußen nichts zu sehen ist, versucht Hamm sich ersatzweise damit zu unterhalten, dass er drinnen im Bunker eine kleine Reise unternimmt. Der besprochene Außenraum, die Mauerschau ins Leere, findet seine komplementäre Ergänzung in Hamms Versuch, im Innenraum

29 Vgl. Deleuze, Gilles: »Erschöpft«, in: Samuel Beckett, He, Joe, Quadrat I und II, Nacht und Träume, Geister-Trio. Filme für den SDR. Booklet zur DVD, Frankfurt am Main: Suhrkamp 2008, S. $18 \mathrm{f}$. 
Regie zu führen. Durchaus anspielungsreich ist diese kleine Weltreise. ${ }^{30}$ Hamms Versuch, sein Zimmer zu umrunden, gemahnt an frühneuzeitliche Weltumsegelung - mit dem Unterschied, dass Hamm nicht außen den Globus, sondern kleinräumlich innen seinen Bunker umrundet. Wenn er an die Wand klopft und diese hohl klingt, gemahnt dies an Nietzsches Philosophie mit dem Hammer. Wenn er schließlich in die Mitte des Raumes zurückkehrt und dort genau in der Mitte sein will, versucht er eine so egozentrische wie eben deshalb idealistische Position zu beziehen.

Trotz dieses Anspielungsreichtums ist nicht zu übersehen, dass und wie Beckett diese Themen szenisch in Spielsituationen umsetzt. Er dekonstruiert historische Positionen, indem er die ihnen zugrunde liegenden Raummodelle offenlegt und das historisch Einmalige auf unterschiedliche Typen von Raumspielen reduziert. Ob man den Globus außen oder innen das Zimmer umrundet, macht kaum einen Unterschied. Gefangen ist man in jedem Fall - ob man nun wie eine Kakerlake die Innenseite abkrabbelt oder wie ein zweidimensionaler Wurm an der Außenseite des Globus klebt. ${ }^{31}$

Aufgrund solcher Abstraktionen kann Beckett Hamms anspielungsreiche Weltreise nicht zuletzt in sein 'Drama einer Phänomenologie der Raumerschließung, integrieren: Hamms Reise an die Wand ist die Mauerschau des Blinden. Da er weder auf die Mauer steigen noch vor ihr etwas sehen kann, muss er die Wand abtasten. Im Kontrast stehen hierbei zwei Erschließungsmöglichkeiten von Raum. Auf der einen Seite die Leiter und die Mauerschau, auf der anderen die Reise und das Klopfen. Beide Zugangsweisen sind präfiguriert durch den Aktionsradius der jeweiligen Figur. Man sieht an dieser Stelle einmal mehr, dass die Raumspiele bei Beckett sich nicht nur auf ein Spiel von Zügen reduzieren lassen. Hamms Fingerknöchel ist das funktionale Äquivalent zu Clovs Fernrohr. Beides sind Rauminspektionswerkzeuge: das eine dient dem Sehenden zur Ferninspektion, das andere dem Blinden zur Nahinspektion.

\section{Verlassen und Tod - Der Raum und der Andere}

Nicht einmal der Tod ist im Endspiel eine Sache der Zeit, sondern eine des Raums - auch wenn es bei Beckett nicht, wie bei Heidegger, um den eigenen Tod, sondern um den des Anderen geht.

30 Hamm spricht in der Tat von einer »kleine(n) Runde um die Welt«; vgl. S. Beckett: Endspiel (wie Anm. 1), S. 239.

31 Von »kleben gebliebenen Würmer(n)« spricht Vilém Flusser; vgl. Flusser, Vilém: »Räume« (1991), in: Jörg Dünne/Stephan Günzel (Hg.), Raumtheorie: Grundlagentexte aus Philosophie und Kulturwissenschaften, Frankfurt am Main: Suhrkamp 2006, S. 274-285, hier S. 274. 
Und weil der Tod des Anderen eine räumliche Angelegenheit ist, ist unentscheidbar, ob der Andere nun tot ist oder einen bloß verlassen hat. Wie Clov weiß, läuft beides ohnehin auf dasselbe hinaus. ${ }^{32}$ Es lohnt, diesen schnoddrig dahingesagten Satz abstrakter zu fassen und seinen philosophischen Gehalt herauszuarbeiten. Die Grundlage des Sozialen ist für Beckett ein Fort-Da-Spiel wie bei Freud in der Psychologie des Kleinkinds, oder aber auch ein Spiel von Präsenz und Absenz wie in anderer Form bei Derrida. Während Heidegger und Sartre Sinn aus dem ausständigen eigenen Tod zu gewinnen versuchen, laborieren die Beckett'schen Helden daran, dass ihr leeres Sein nicht enden will. Einsam sind sie nicht deshalb, weil sie in einer unvertretbaren Weise den eigenen Tod auf sich nehmen müssen, sondern weil der Andere aufgrund eines strikt räumlichen Chorismos unerreichbar ist. Unter der Hand setzt Beckett damit dem existenzialistischen Szenario des eigenen Todes ein spiegelverkehrtes entgegen. Es basiert nicht auf dem eigenen Tod - und in abkünftiger Weise auf Zeitlichkeit und Sinn -, sondern auf Tod und Absenz des Anderen. Die Fundamentalkategorie solcher Absenz ist der Raum, nicht die Zeit.

In aller Konsequenz und Komik spielt Beckett die Aporien der Absenz des Anderen durch. Als Clov Hamm das erste Mal ankündigt, ihn zu verlassen, fragt er ihn, wie er (Hamm) davon Kenntnis erhalten könne. Er (Clov) könne schließlich auch in der Küche gestorben sein. Gewollt abstrus und aporetisch versuchen Hamm und Clov dieses Problem der Absenz des Anderen, diese Logik des Raums in eine der Zeit zu überführen. Den durchaus plausiblen ersten Lösungsansatz Clovs - wenn er, Clov, Hamm nicht verlassen habe, sondern nur in der Küche gestorben sei, werde Hamm das daran merken, dass er zu stinken anfange - pariert Hamm mit der Entgegnung: "Du stinkst jetzt schon." ${ }^{33}$ Natürlich ist das Nonsens. Wenn Clov in der Küche gestorben ist, wird der Gestank zunehmen, wenn er Hamm jedoch verlassen hat, wird er abnehmen.

Wie wenig das Fort-Da zwischen Verlassen und Tod unterscheiden kann, aber auch wie abkünftig Beckett die Kategorie der Zeit denkt, zeigt sich in Clovs abschließendem Lösungsansatz:

Clov: $\quad[\ldots]$ Ich hab's. Ich ziehe den Wecker auf.

Pause [...]

Du pfeifst mir. Ich komme nicht. Der Wecker rappelt.

Ich bin weg. Er rappelt nicht. Ich bin tot. ${ }^{34}$

32 Vgl. ebd., S. 265.

33 Ebd.

34 Ebd., S. 267. 
Das Zeitwerkzeug Wecker ist in diesem Konstrukt kaum mehr als ein Apparat, der dazu dient, die primär räumliche Absenz des Anderen zu kodieren. Begründete Bedenken hat deshalb Hamm. Hinter seiner Frage "Geht er [der Wecker] überhaupt?" klingt die grundsätzlichere an, ob das Problem der Absenz des Anderen überhaupt mit Instrumenten der Zeit zu bewältigen ist. Nachgerade magisch sind deshalb die Eigenschaften dieses Weckers: Er kann, Clov zufolge, "Tote aufwecken! "

Während die vorstehende Szene den Tod des Anderen wie beiläufig mit dem Verlassen verbindet, ist er in der Schlussszene kontrapunktisch gesetzt. Er verteilt sich dort auf zwei Personen: Clov will Hamm verlassen und er sagt ihm das in aller Deutlichkeit. Gegenbildlich - und äußerst zweideutig - ist demgegenüber die Ankunft des Knaben kodiert: "Wenn er existiert, kommt er hierher oder er stirbt dort. Und wenn er nicht existiert..." ${ }^{36}$

In inverser Form kehrt das Fort-Da-Spiel zwischen Clov und Hamm an dieser Stelle wieder. Das Noch-Nicht-Da, die Ankunft des Knaben, erweist sich als kaum weniger zweideutig als das NichtMehr-Da Clovs, mit dem dieser Hamm ständig droht. Zweideutig, und das heißt in einem durchaus räumlichen Sinne: uneinsehbar, ist bei Beckett alles, was nicht da ist. Zuvörderst das Nicht-Da-Sein des Anderen: Sei es nun Godot, Clov oder der Knabe im Endspiel. Zumal das Endspiel geht dazu über, das Nicht-Da-Sein des Anderen zu verweltlichen, und das heißt: zu entzeitlichen und zu verräumlichen. Während man bei Warten auf Godot zumindest noch die Frage aufwerfen kann, ob Godot eine Persiflage auf Gott, und das heißt: auf einen externen Beobachter und Sinngeber ist, verbietet sich eine solche Spekulation spätestens mit dem Endspiel. Der Fortschritt oder auch nur die Vereindeutigung des Endspiels gegenüber Warten auf Godot besteht darin, dass das Nicht-Da-Sein des Anderen als rein räumliche, uneinsehbare Absenz gefasst ist. ${ }^{37}$ Bist $\mathrm{du}$ nicht da, weil du tot bist, weil du nicht existierst oder weil du mich verlassen hast? Selbst auf diese grundlegenden Fragen kann das Fortsein des Anderen keine Antwort geben. Die Absenz des Anderen und - grundsätzlicher gefasst - der Raum kennt keine Gründe und keinen Sinn. Die Frage, ob Godot kommen wird, und insbesondere die, ob er überhaupt kommen will, hat sich erübrigt. Unter den Auspizien der Räumlichkeit des Anderen ist nur eines gewiss: Dass er nicht da ist. Alles Weitere wäre spekulativer Intentionalismus.

35 Ebd.

36 Ebd., S. 309.

37 In der Handlungsführung spiegelt sich diese Verschiebung in der Figur des Knaben. In Warten auf Godot ist der Junge eine Mittlerfigur zwischen Godot und den Wartenden, im Endspiel tritt der Knabe selbst nicht mehr auf. 
Ohne einen strikt wirkungsgeschichtlichen Bezug auf Heidegger behaupten zu wollen, lässt sich im Kontrast zu ihm zeigen, wie bei Beckett Raumdenken sich nachgerade verabsolutiert. Auch wenn Heidegger idealistische Erkenntnistheorie mit dem raumtheoretischen ${ }^{38}$ Verweis kassiert, Dasein sei In-der-Welt-sein, auch wenn er breit eine 'Phänomenologie، des Platzes ausarbeitet, sind weitere zentrale Kategorien seines Denkens wie das "Mitsein" und der eigene Tod nicht von Raumbegriffen geprägt. Beckett fasst selbst diese beiden Themen räumlich auf. Er streicht den eigenen Tod als sinngebende Instanz und verräumlicht das "Mitdasein der Anderen. ${ }^{39}$ Der Andere ist fort oder er ist da. Das ist - anders als bei Heidegger - kein eigenständiges Existenzial, sondern eine durch und durch räumliche Angelegenheit. Während Heideggers "Dasein" der eigene Tod gewiss ist, stellt das Endspiel die Ungewissheit des Todes des Anderen ins Zentrum. Aus Gewissheiten kann man Sinn ableiten, aus Ungewissheiten nicht. Das ungewisse Fort-Sein des Anderen ist deshalb nicht eine Sache des Sinns, sondern eine des Kalküls. Es löst die Ungewissheit in Eventualitäten auf, die alle gleich-möglich und deshalb gleich-gültig sind. Deshalb lässt sich im Gegenzug nicht einmal mehr über Leben und Tod des Anderen entscheiden:

Clov: Wenn ich diese Ratte nicht töte, wird sie sterben. ${ }^{40}$

Hamm: hört auf zu gähnen: Na ja, geh ihn [den Knaben] ausrotten [...]. Tu deine Pflicht! [...] Nein, laß nur. ${ }^{41}$

Exemplarisch zeigt sich am Tod des Anderen, wie wenig der Beckett'sche Raum von Entscheidungen abhängt, wie wenig er deshalb situativ zu verstehen ist. Er regt zum Gähnen an, er langweilt bis zur Erschöpfung, weil alles, was möglich ist, bereits als Möglichkeit gegeben ist, und weil deshalb das Mögliche sich nicht länger oder nur um den Preis von Vorlieben realisieren lässt. Diese jedoch schöpfen, Deleuze zufolge, das Mögliche nicht aus. ${ }^{42}$

38 Ich übernehme den Begriff der Raumtheorie aus dem Titel des von Jörg Dünne und Stephan Günzel herausgegebenen Bandes Raumtheorie (wie Anm. 31), obwohl er nicht ganz unproblematisch ist, wenn man ihn isoliert verwendet. Streng genommen gibt es Raumtheorie nicht. Sie ist stets im Kontext eines philosophischen Systems zu sehen. Da das hier nicht zu leisten ist, vgl. zu Heidegger Günzel, Stephan: »Einleitung« [zu Teil II: Phänomenologie der Räumlichkeit], in: ebd., S. 105-128, hier S. 116-120.

39 M. Heidegger: Sein und Zeit (wie Anm. 4), S. 117.

40 S. Beckett: Endspiel (wie Anm. 1), S. 293.

41 Ebd., S. 305.

42 Vgl. G. Deleuze: »Erschöpft« (wie Anm. 29), S. 7f. 


\section{Regie aus dem Off Innen- und Außenraum in den späteren Stücken}

So geschlossen die Beckett'schen Räume sind, so sehr sind sie stets auf einen Außenraum bezogen. Das Außen ist in Warten auf Godot Godot, der nicht kommt. Es kehrt im Endspiel als Mauerschau, als Blick in einen ereignislosen Außenraum wieder. Markanter noch sind andere, zumeist spätere Stücke - einsetzend mit Spiel ohne Worte - von einem Außen bestimmt. ${ }^{43}$ In Spiel ohne Worte I erhält eine Figur vom Schnürboden herab Gegenstände angeboten, die ihr stets wieder entzogen werden. In Spiel ohne Worte II werden zwei Spieler abwechselnd von einem Stachel angestoßen. In Glückliche Tage beginnt Winnie zu reden, wenn es klingelt. In vergleichbarer, jedoch stilisierterer und durchgängigerer Weise heben die Figuren in Spiel zu sprechen an, wenn sie von einem Scheinwerfer angestrahlt werden, um abrupt einzuhalten, wenn der Scheinwerfer eine andere Figur anleuchtet. In Kommen und Gehen schließlich ist die Handlung dadurch skandiert, dass von drei Figuren abwechselnd eine die Bühne verlässt, um so den anderen beiden zu ermöglichen, hinter ihrem Rücken zu reden. Vergleichbare Bewegungsmuster von Bühnenauftritt und -abgang sind in Quadrat zu verzeichnen: Dort umkreisen vier Figuren einen imaginären Punkt, so als wären sie von einem Magnetfeld wechselweise angezogen und abgestoßen.

Gemessen am Endspiel neu an dieser Spielanordnung ist, dass in ihr nicht länger ein ereignisloser Außenraum besprochen wird oder der Innenraum Gegenstand von Raumspielanweisungen ist. Stattdessen ist die Regie - oder aber auch das Drama - wie in den Außenraum verlagert. Deutlich wird diese Regiehaftigkeit bereits in Spiel ohne Worte I. Wenn etwas vom Schnürboden gereicht wird, ertönt ein Pfiff. In Spiel ohne Worte II werden die Figuren von dem von außen eindringenden Stachel angespornt, sich zu bewegen. Anweisungs- und Regiecharakter hat beides, das Pfeifen und der Stachel. Der Befehl lautet hier wie dort: 'Beweg dich! Er kehrt in anderer Form in Spiel wieder. Dort lautet der Befehl: 'Sprich, wenn du angeleuchtet wirst!

Ich rede von einer Regie aus dem Off und nicht bloß von einem dramatischen Einwirken des Außenraums, weil der Außenraum bei Beckett nicht nur handlungswirksam ist, sondern traditionelle Raum- und Aufführungskonzepte des Theaters zitiert. Die Klingel in Glückliche Tage gemahnt an die Pausenklingel, der Lichtwechsel in Spiel zitiert Szenenwechsel und Vorhang, Kommen und Gehen spielt

43 Bei der französischen Erstaufführung von Endspiel wurde Spiel ohne Worte mit aufgeführt, vgl. Esslin, Martin: Das Theater des Absurden. Von Beckett bis Pinter, Reinbek bei Hamburg: Rowohlt 1965, Neuausgabe 2006, S. 28. 
mit dem Bühnenauftritt und -abgang einzelner Figuren. Neu bei Beckett ist, dass er die rein technischen Bedingungen räumlicher Aufführung - wie bereits in der Mauerschau im Endspiel - zum integralen Bestandteil der Handlung erhebt. Anders als in der Clov'schen Mauerschau ist in den späteren Stücken der Raum jedoch alles andere als inert. Sie überführen die besprochene Regie, von der das Endspiel noch geprägt ist, in ein reines Raumspiel. Während Hamm und Clov sich noch damit abmühen, den leeren Außenraum zu besprechen, wird dieser in den späteren Stücken selbst zum Akteur. Das ist durchaus konsequent: Da der Raum für Beckett eine fundamentale Kategorie ist, geht er in zunehmendem Maße dazu über, ihn in seiner Wirkmächtigkeit zu zeigen. Durchaus programmatischen Charakter hat deshalb Spiel ohne Worte: Die strikte Hinwendung zum rein Pantomimisch-Räumlichen, der aktive Außenraum ersetzt den besprochenen Außenraum des Endspiels.

Pointierter als im Endspiel ist deshalb auch die Beziehung von Zeit und Raum gefasst. Während Hamm und Clov noch in durchaus beredter Weise beklagen, dass draußen nichts geschieht, zeigt Spiel ohne Worte, dass an der Schnittlinie von Draußen und Drinnen durchaus etwas geschieht. Freilich immer dasselbe. Damit ist eine weitere Zäsur beschritten. Auch wenn das Endspiel die Zeit in Warten auf Godot weitgehend durch den Raum ersetzt, besitzen beide Werke eine wesentliche Gemeinsamkeit: Sie stehen noch in der Dimension des Sinns, weil sie Sprachkunstwerke sind. Sie können diese Dimension zwar negieren, sich ihrer aber nicht vollständig entledigen. Positiver, eigenständiger an Raumkonzepten ausgerichtet ist demgegenüber die Regie aus dem Off. Sie ersetzt die besprochene ereignislose Leere von Raum und Zeit durch ein iteratives Bewegungsspiel, und das heißt: durch ein Raumspiel im strengen Sinne des Wortes. Raumspiele sind iterativ. In der Iteration zeigt sich das, was im Drama sonst zu besprechen ist, als Regel.

Gemessen am Endspiel hat diese Neuausrichtung durchaus auch ihren Preis. Die phänomenologische Breite des Endspiels verdankt sich dem Umstand, dass es in der Grundanlage noch von Resten der dramatischen Figur, und das heißt insbesondere: der redenden Figur geprägt ist: "Lass uns eine kleine Reise machen", "Schau aus dem Fenster!", "Wie werde ich wissen, ob du tot bist?" Augenscheinlich ist die Vielfalt der Raummodelle im Endspiel dem Umstand geschuldet, dass redende Figuren zu einem Raumspiel einladen und dieses eröffnen können. In dem Maße, wie Beckett, einsetzend mit Spiel ohne Worte, die letzten Reste der dramatischen Figur zugunsten eines reinen Raumspiels preisgibt, sind solche Übergänge nicht mehr möglich. Nach dem Endspiel kann Beckett deshalb nur noch zumeist kurze Stücke entwickeln, die jeweils nur einen einzigen Raumspieltyp vorführen. Die Dressur in Spiel ohne 
Worte I, das Weg-Da in Spiel ohne Worte II, indiskretes Gerede in Kommen und Gehen, ein Modell von Kollision und Attraktion in Quadrat. Die Vielschichtigkeit der Raumspiele, die das Endspiel noch bieten konnte, zerfällt in eine facettenreiche Vielzahl zumeist miniaturhafter Einzelwerke.

Beckett hat versucht, diese Vielfalt gleichwohl zu bündeln: Durch zunehmende Abstraktion. Zumal Quadrat - das letzte Werk, das ein Raumspiel im engeren Sinne des Wortes ist ${ }^{44}$ - erscheint wie die Summe aller Beckett'schen Raumspiele. Während man den frühen Stücken noch einen sachlichen Gehalt zuschreiben kann, während die frühen Stücke noch mit konkreten Inszenierungsmitteln wie Stachel, Kamera und Scheinwerfer arbeiten, ist die Spielanordnung in Quadrat auf ein Minimum reduziert. Ein Quadrat, ein Punkt, vier Personen, eine Matrix, die die Laufwege sowie Bühnenauftritt und -abgang reguliert. Die Figuren in Quadrat messen den Raum in seiner kombinatorischen Festgelegtheit bis zur Erschöpfung aus. ${ }^{45}$ Sie lassen ihn als reinen Spielraum erscheinen, indem sie ihn wieder und wieder nach immer derselben Regel abschreiten. Wie sehr Raumspiele auf dem Prinzip der Iteration basieren, zeigt sich auch hier. Es hätte genügt, diese Kombinatorik im besten Fall einmal, der Deutlichkeit halber zweimal und für die Dummen dreimal durchzuspielen. Beckett wiederholt sie x-mal. Er variiert das Spiel allenfalls, um es einmal mehr zu abstrahieren: Quadrat I zeigt schlurfende farbige Figuren, die von einem Trommelspiel begleitet werden. Quadrat II zeigt dieselben Figuren im Beckett-üblichen Grau-in-Grau, ohne Begleitmusik, so als ginge es darum, den abstraktiven Charakter dieses Metaspiels auszustellen, indem es einer weiteren Abstraktion unterzogen wird.

Trotz oder aber auch aufgrund seiner Abstraktheit greift Quadrat Grundmuster der früheren Raumspiele auf und wandelt sie ab. So wie Hamm in seiner kleinen Weltreise an der Mauer entlang fährt und zum Mittelpunkt strebt, so auch die Figuren in Quadrat. In inverser Form kehrt demgegenüber das Motiv des leeren Außenraums wieder: Es ist in Quadrat wie nach innen gestülpt. Während die Protagonisten in Warten auf Godot und im Endspiel darauf warten, dass von außen etwas eintritt, werden sie in Quadrat von einem leeren Nichts, von dem schwarzen Punkt in der Mitte zugleich angezogen und abgestoßen. Eine Begegnung der Figuren findet nicht

44 Unter Raumspielen im engeren Sinne sind an dieser Stelle Raumspiele zu verstehen, bei denen vorrangig bühnentechnische oder aber auch filmtechnische Spielbewegungen im Vordergrund stehen. Vergleichsweise schwach ausgeprägt ist in diesen Spielen zumeist die Achse von Raumspiel und Zuschauerraum.

45 In diesem Doppelsinn beschreibt Deleuze das Beckett'sche Werk und Raumkonzept; vgl. G. Deleuze: »Erschöpft« (wie Anm. 29), S. 21-25. 
statt: Der Andere ist außen. Der schwarze Punkt in der Mitte ist der Platzhalter dieses Außen. Er wirkt selbst dann, wenn sich nur eine einzige Figur in Quadrat bewegt. Auch diese macht um das Außen einen Bogen. Man würde das Außen des Anderen viel zu konkret auffassen, wenn man es von der physischen Existenz des Anderen abhängig machen wollte. Bereits das Endspiel eröffnet die Möglichkeit, den Anderen auszurotten, ihn zu erwarten oder draußen sterben zu lassen, sofern er denn überhaupt existiert.

\section{Das Außen des Zuschauerraums}

Tendenziell verändert die Regie aus dem Off nicht nur die Beziehung von Bühnenraum und Regieaußenraum, sondern auch die von Bühne und Zuschauerraum. Wenn in Spiel ohne Worte von außen ein Stachel einwirkt oder Gegenstände dargeboten werden, bleibt der eigentliche Akteur des Stückes uneinsehbar. In Spiel ohne Worte ist dieser uneinsehbare Aktionsraum noch vergleichsweise traditionell lokalisiert. Er liegt über der Bühne oder seitlich zu ihr, das heißt: er ist vorrangig auf das Bühnengeschehen und nicht auf den Zuschauerraum bezogen. Spiel radikalisiert diese Anordnung. Es verlagert die Regie aus dem Off - das sind in diesem Falle die Scheinwerfer, die die Protagonisten zum Sprechen bringen - in den Rücken des Zuschauers. Der Regieaußenraum ist damit nicht mehr bloß uneinsehbar, er umschließt von hinten den Zuschauerraum.

Das ist, gemessen am Endspiel - aber auch im Vergleich zum traditionellen Theater -, ein grundsätzlich neues Arrangement. Die Illusionseffekte des alten Theaters zerstört bereits der Mauerschauer Clov, wenn er sein Fernrohr in den Zuschauerraum richtet und sagt: "Ich sehe ... eine begeisterte Menge." ${ }^{46}$ Der späte Beckett setzt dieses Mittel nicht mehr ein. Das heißt jedoch nicht, dass er zur vierten Wand zurückkehrt. ${ }^{47} \mathrm{Ab}$ Spiel bezieht er eine dritte Position. Exemplarisch ablesbar ist diese an dem Außen, das die Scheinwerfer eröffnen. Anders als die vierte Wand bieten sie keinen guckkastenhaften Einblick in einen intimen, da unbeobachteten (Privat-)Raum, sondern inszenieren ein Geschehen, das für den Zuschauer in einsehbarer Weise uneinsehbar ist. Diese Wende ist nicht nur von formalem, sondern auch von inhaltlichem und das

46 S. Beckett: Endspiel (wie Anm. 1), S. 245. Das Motiv findet sich im Übrigen bereits in Warten auf Godot.

47 So eben hat man die Berliner Inszenierung gedeutet; vgl. Schulz, GeorgMichael: „Samuel Becketts Theater: Räume, Körper und Personen«, in: Helmut Siepmann/Kaspar Spinner (Hg.), Moderne und Gegenwart. Meisterwerke der Weltliteratur Bd. V, Bonn: Romanistischer Verlag 1992, S. 47-69, hier S. 51. 
heißt, genauer gesagt, von subjekttheoretischem/anthropologischem Belang: Bekanntlich verbessert das Konzept der vierten Wand nicht nur die Regiepraxis und deren illusionäre Effekte, sondern transportiert zugleich ein neues Menschenbild. Deutlich ist dieser Bezugspunkt bei Diderot gesetzt: "Wenn man dich nicht sieht, wenn du dich der Öffentlichkeit entziehst, bist du du selbst, bist du ein Mensch." ${ }^{48}$ Ausgehend von dieser Beobachtung entwickelt Diderot das Modell der vierten Wand: Auf Gemälden und auf dem Theater sollen die Figuren so agieren und so dargestellt sein, als wüssten sie nicht, dass sie von einem Zuschauer betrachtet werden. ${ }^{49}$ Mensch (oder aber auch Bürger) ist man der Theorie der bürgerlichen Aufklärung zufolge, wenn man nicht repräsentieren muss. Moderne Subjektivität gründet mit in dieser paradoxen Nische einer Beobachtung vorgeblich unbeobachteter Intimität aber auch modernes Verstehen. In dem Maße, wie der Zuschauer die Figuren gleichsam belauscht, leiht er ihnen sein Ohr. Die vierte Wand lädt zu einer mitfühlenden Teilnahme, zu einem SichVersetzen-in-fremdes-Leben ein. Die psychologische Hermeneutik Schleiermachers, die Verstehen als Sich-Versetzen-in-fremdes-Leben deutet, ist der späte Nachhall solcher Aufführungskonzepte.

Ganz anders sind Raumkonzept und Bühnenanordnung beim späten Beckett verfasst. Während Diderot mit der vierten Wand die Position des Zuschauers streicht, um ein imaginäres Selbstsein des Menschen zu etablieren, führt Beckett in Spiel einen imaginären, da uneinsehbaren Beobachter ein, von dem sich die Figuren gesehen wissen und dessen Fokalisierung sie zum Sprechen veranlasst. Während das Konzept der vierten Wand auf ein selbstbestimmtes, da unbeobachtetes Subjekt zielt, inszeniert Spiel Scheinwerfer-

48 Vgl. Diderot, Denis: Essais sur la peinture, in: ders., CEuvres, Bd. 4: Esthétique - Théâtre, hg. von Laurent Versini, Paris: Laffont 1996, S. 467516, hier S. 490: »Vous êtes seul chez vous. [...] Vous voilà étendu sur votre chaise de paille, les bras posés sur vos genoux, votre bonnet de nuit renfoncé sur vos yeux, ou vos cheveux épars et mal retroussés sous un peigne courbé; votre robe de chambre entrouverte [...]. On vous annonce M. le marquis de Castries; et voilà le bonnet relevé, la robe de chambre croisée; mon homme droit, tous ses membres bien composés; se maniérant, se marcélisant, se rendant très agréable pour la visite qui lui arrive $[\ldots . . . \ll$

49 Nachgerade bildhaft führt Diderot dies an der Aufführung des Fils naturel in einem Wohnzimmer vor, der er, der Fiktion zufolge, als verborgener Zuschauer beiwohnt; vgl. Diderot, Denis: Le fils naturel, in: ders., CEuvres, Bd. 4: Esthétique - Théâtre (wie Anm. 48), S. 1081-1127, hier S. 1083: "'entrai dans le salon par la fenêtre; et Dorval, qui avait écarté tout le monde, me plaça dans un coin, d'où, sans être vu, je vis et j'entendis ce qu'on va lire $[\ldots] . \ll$ 
marionetten, Figuren, die von einem Beobachter gesteuert werden. Die hohe Kunst Beckett'scher Raumregie zeigt sich daran, dass er mit minimalen Änderungen in der Bühnenanordnung einen neuen 'Subjekt-Begriff, ganz ohne Philosophie formulieren kann. Er hat sich diese Position Zug um Zug erarbeitet. Der frühe Beckett operiert noch mit vergleichsweise reflexiven Mitteln. Er dekonstruiert das Subjekt, indem er seine Theaterhaftigkeit ausstellt. "Jetzt spiele ich", "Ich sehe ... eine begeisterte Menge." Ab Spiel tritt dieser dekonstruktive Ansatz zurück, ab Spiel geht Beckett nicht länger eine dekonstruktive Kumpanei mit dem Zuschauer ein, sondern bezieht ihn in das Spielgeschehen mit ein, nicht im Sinne der Guckkastenbühne, sondern indem er ihn von außen umgreift.

Man muss sich deshalb nicht länger in das versetzen, was vorne auf der Bühne geschieht, man muss nicht länger darüber nachdenken, wie sich die Akteure da vorne zum Außen stellen, weil es einem selbst im Nacken sitzt. Einmal mehr unterläuft an dieser Stelle Beckett vermittels eines Raumkonzepts traditionelle Sinnund das heißt in diesem Fall: Verstehensmodelle. Während das Modell der vierten Wand den Raum dazu nutzt, das Verstehen des Anderen zu ermöglichen, weist der späte Beckett dem Zuschauer seinen Platz an. $\mathrm{Zu}$ verstehen gibt es hierbei nichts. Man ist im Raum und sitzt an dessen Grenzlinien und Faltungen. Keine Verstehensgemeinschaft, die sich daraus ergäbe, dass Zuschauer und Bühnenfigur gleichermaßen demselben Außen ausgesetzt sind, entsteht hierbei. Das Außen ist viel listiger als solch hermeneutisch einfühlende Vernunft. Es nistet sich überall ein: Im Intimraum der Clov'schen Hose, aber auch im Außen des Zuschauerraums, indem es die vierte Wand nicht länger einreißt, sondern spaltet.

Wie wenig ein interpretativer Zugriff bei solchen Raumkonzepten angebracht ist, lässt sich an Film nachzeichnen: Beckett bestimmt in einer Vorbemerkung das Raumgeschehen, das Film entfaltet, in strikt philosophischer Weise:

»sse est percipi.

Wenn alle Wahrnehmung anderer - tierische, menschliche und göttliche aufgehoben ist, behält einen die Selbstwahrnehmung im Sein.

Die Suche nach dem Nicht-Sein durch Flucht vor der Wahrnehmung anderer scheitert an der Unausbleiblichkeit der Selbstwahrnehmung. ${ }^{50}$

Um sogleich hinzuzusetzen, dass diese Aussage keinen Wahrheitswert habe, sondern als Regieanleitung zu verstehen sei. Damit kehrt Beckett die traditionelle Beziehung von Aufführung und Interpretation um. Es geht ihm nicht darum, aus Stücken eine zugrunde-

50 Beckett, Samuel: Film, in: ders., Nacht und Träume. Gesammelte kurze Stücke, Frankfurt am Main: Suhrkamp 2006, S. 187-205, hier S. 189. 
liegende Philosophie oder aber auch Wahrheit herauszulesen, sondern darum, die der Philosophie inhärierenden Raummodelle zu inszenieren. Nur in der Inszenierung, nur wenn man Philosophie als Regieanweisung auffasst, versteht man sie. Man versteht sie erst dann, weil Räume nur zu verstehen sind, wenn man sich in sie hineinbegibt.

Dabei ist nicht zu übersehen, dass Film die Raumanordnung von Spiel der Sache nach invertiert. Film zeigt, wie ein Auge A ein Objekt O verfolgt. Die Verfolgung ist mit Mitteln der Kameraführung dargestellt. Man sieht das Auge selbst nicht (zumindest nicht anfänglich), sondern nur das, was es sieht: den Rücken eines verfolgten und fliehenden Mannes, den Rücken von O. Hineingezwängt in diese Kameraperspektive nehmen wir als Zuschauer mit der Kamera die Verfolgung von $\mathrm{O}$ auf. Invers verhält sich Film zu Spiel, weil wir uns genau dort befinden, wo in Spiel die Scheinwerfer sind: Am Aktionspol, am Ort der Regie aus dem Off, also im Außen. Selbstredend lässt Beckett nicht zu, dass wir uns in diesem Logenplatz des Außen einrichten. In einem finalen Wechselbild ${ }^{51}$ kippt die Beziehung von Auge und Objekt. Man sieht nicht nur den Rücken des Objekts, sondern auch sein Gesicht, aber auch das Gesicht des Auges. Im Vergleich zu Spiel zeigt sich, wie explorativ und nachgerade systematisch Beckett das Außen des Zuschauerraums auslotet. Er setzt uns in Film an das Außen von Spiel, um selbst dieses zu spalten und mit einem Gegenblick zu konfrontieren. Medienreflexiv unterläuft er hierbei das gängige Mittel der Kameraführung, das uns in Fortsetzung der Guckkastenbühne eine identifikatorische Beobachterperspektive aufzwängt.

So wie in Spiel ohne Worte und Kommen und Gehen die Regie aus dem Off mit vergleichsweise traditionellen Mitteln gestaltet ist, so auch in Spiel und Film das Außen des Zuschauerraums. Weder Kameraführung noch Scheinwerfer sind besonders innovative Stilmittel. So wie in Quadrat wartet der spätere Beckett auch bei der Integration des Zuschauerraums mit ausgefeilteren Konzepten auf, so etwa in seinen Fernsehspielen.

Teilweise ist diese Abwandlung medien- und aufführungsbedingt. Man kann im Wohnzimmer, anders als im Theater, keine rückwärtigen Scheinwerfer montieren. Beckett setzt deshalb in seinen Fernsehspielen ein weiteres Mittel ein: die Stimme. Auch sie - und nicht nur Bildmittel wie Kameraführung und Scheinwerfer kann einen Außenraum erzeugen. Das lässt sich exemplarisch an He, Joe zeigen: Man sieht in diesem Fernsehspiel einen Mann, der von einer weiblichen Stimme heimgesucht wird, die ihm Vorhal-

51 Beckett war sich nicht sicher, wie diese Beziehung filmisch darzustellen sei; vgl. ebd., S. $201 \mathrm{f}$. 
tungen macht. Ich will nicht weiter untersuchen, wer sich hinter dieser Stimme verbirgt, sondern Aspekte der Raumregie in den Vordergrund stellen. Von woher spricht diese Stimme? Augenscheinlich von nirgendwoher. Es ist eine akusmatische Stimme. Da wir gewohnt sind, Sprecher zu lokalisieren und Stimmen Sprechern zuzuordnen, entsteht, wo diese Zuordnung nicht möglich ist, der Eindruck des Nirgendwoher. In dem Maße, wie He, Joe und weitere Fernsehspiele Becketts diese Zuordnung verweigern, eröffnet die Stimme einen Außenraum, der in diesem Fall über die Trennung von sprechendem Mund und gehörter Stimme verläuft. Wie man sieht, versteht sich Beckett darauf, selbst in den bauartbedingten Guckkasten, der das Fernsehen ist, einen Außenraum zu implementieren.

Beckett setzt in He, Joe nicht nur die akusmatische Stimme ein, sondern auch das traditionelle Mittel der Kameraführung, wenn auch in durchaus markanter Weise. Die Kamera umkreist Joe, sie rückt ihm in zunehmendem Maße auf den Leib. Obwohl wir Joe nur mit den Augen der Kamera sehen, lädt diese uns nicht dazu ein, ihre Perspektive zu teilen. Das hat der Sache nach sicherlich damit zu tun, dass diese Kamera viel zu aufdringlich ist, als dass wir ihre Perspektive einnehmen wollten. Regietechnisch beruht diese Distanz zur Kameraperspektive auf einem weiteren Kopplungseffekt. Die Kamera bezieht die Perspektive der akusmatischen Stimme. Wie diese rückt sie Joe zusehends auf den Leib. Sie umkreist ihn, sie kommt näher. Die medientechnische und zugleich wahrnehmungspsychologische Raffinesse von He, Joe besteht darin, die beiden Kanäle Lippenbewegung und Stimme zu entkoppeln, um im Gegenzug den Kanal der akusmatischen Stimme mit der Kameraperspektive zu verkoppeln.

Gemessen an dem Stummfilm Film, der das Außen der Kameraperspektive nur mittels eines Perspektivewechsels darstellen kann, ist diese Verschaltung der Kanäle ungleich avancierter. Während die Beschränkung auf den Stummfilm das Außen nur in einem nicht in jeder Hinsicht überzeugenden finalen Doppelbild darstellen kann, ${ }^{52}$ erlaubt die Einführung des Tonkanals eine ungleich durchgängigere und suggestivere Präsenz des Außen. Und dennoch greift Beckett in He, Joe auf das in Film entwickelte Modell des Wechselblicks zurück. Die Erstfassung von He, Joe zeigt in der Schlusseinstellung anfänglich Joe in leichtem Seitenprofil, um dann Joes Gesicht frontal zu fokussieren. Die Stimme verstummt, Joe schlägt die Augen auf. Die Kameraperspektive neigt sich nach unten und zeigt einen zwar grinsenden, aber nicht sprechenden Mund. So sehr

52 Beckett selbst war mit dieser Lösung nicht ganz zufrieden; vgl. ebd., S. 202. 
Joe über weite Strecken in der einseitigen Perspektive eines passiven esse est percipi steht, so sehr durchbricht er diese zum Schluss: Er blickt den Zuschauer an. Er blickt - wie das O in Film zurück mit der entscheidenden Differenz, dass er nicht wie in Film seinen Verfolger, sondern den Zuschauer vor dem Fernseher anblickt. Auch an dieser zugespitzten Wiederaufnahme von Film ist ablesbar, dass und wie Beckett in zunehmendem Maße den $\mathrm{Zu}$ schauerraum besetzt: In He, Joe ist der Gegenblick nicht bloß Gehalt eines Films. Er konfrontiert den Zuschauer als Betrachter des Films. Einmal mehr erreicht Beckett diesen Effekt durch eine präzise Ver- und Entkopplung von Ton-/ Bildkanal und Kameraführung.

$\mathrm{Ab}$ Spiel ohne Worte ist es nicht länger erforderlich, den (Außen)Raum zu besprechen, weil der Außenraum von diesem Stück an selbst wirksam ist. Beim späten Beckett ist er sogar in zunehmendem Maße der Ort der Stimme. Dennoch greift Beckett das Motiv des besprochenen Raums, das für Endspiel so prägend war, in Geister-Trio wieder auf. Man sieht einen karg, nachgerade schematisch möblierten Raum - Fenster, Türe, Pritsche, Hocker -, den redundanter Weise eine Stimme beschreibt: "Nuancen der Farbe Grau. Pause. Man verzeihe, daß ich erwähne, was offensichtlich ist." ${ }^{53}$ So sehr hier - wie im Endspiel - ein weitgehend entleerter Raum besprochen wird, so unübersehbar sind die Differenzen: Im einen Fall wird der leere Außenraum besprochen, im anderen Fall bespricht eine Stimme von außen einen kaum weniger entleerten Innenraum.

Durchaus in diesem Sinne wandelt Beckett das Motiv der Raumregie und der Regie aus dem Off ab. Man sieht eine Figur auf dem Hocker, die abwechselnd zum Fenster und zur Türe geht, um diese zu öffnen und wieder zu schließen. Die Stimme weist sie an, dies zu tun: "Jetzt zur Tür. [...] Niemand. Pause. 5 Sekunden. Öffnen. [...] Niemand." ${ }^{54}$ In einer letzten Verknappung reduziert sich die Regie aus dem Off auf die Stimme aus dem Off. Und diese beschränkt sich aufs Wesentliche: Auf den tonlosen Befehl, sofern man Infinitive wie "öffnen" und "schließen" als imperativische Infinitive lesen will.

Zumal an dem Konzept der Raumregie ist ablesbar, wie konsequent Beckett seine Fragestellungen weiterentwickelt. "Lass uns eine Reise machen": Die Raumregie im Endspiel ist, so sehr das Stück zunächst irritieren musste, noch in durchaus traditioneller Weise binnendramatisch. Es bindet die Raumregie in die Handlung

53 Beckett, Samuel: Geister-Trio, in: ders., Nacht und Träume (wie Anm. 50), S. 263-274, hier S. 266.

54 Ebd., S. 268. 
ein. Demgegenüber steuern die Scheinwerfen in Spiel das Drama von außen und zerstückeln hierbei die Eifersuchtsgeschichte, um die es der Sache nach geht, bis zur Unkenntlichkeit. "Sprich, wenn du angeleuchtet wirst", lautet ihre implizite Botschaft. So sehr hierbei das Drama ins Außen gesetzt und die Handlung veräußerlicht ist, so sehr besitzen die Scheinwerfer - ähnlich wie auch die Stimme in $\mathrm{He}$, Joe - noch dramatischen Charakter: Sie fordern den Akteur auf der Bühne zum Sprechen bzw. zum Zuhören auf. Anders ist die Stimme in Geister-Trio verfasst. Sie weist nur noch auf das hin, was offensichtlich zu sehen ist.

»Man sehe nun näher hin. Pause. Fußboden. [...] Staub. Pause. Wer dieses Stück Fußboden gesehen hat, hat inn ganz gesehen. Wand. [...] Staub. Pause. Jetzt, da klar ist, was für eine Wand - [...] Was für ein Fußboden - [...] Sehe man nochmal hin. ${ }^{55}$

Das ist ein nachgerade phänomenologischer Grundgestus: Die Aufforderung zu sehen, was zu sehen ist, und es von jeder weiteren Deutung freizuhalten. $\mathrm{Zu}$ sehen ist der Raum, nichts weiter. Wenn es denn Bedeutung gibt, ist sie aus ihm herauszulesen.

Aufgrund dieser Zuspitzung ist eine weitere Differenzierung des (Außen)Raums möglich. Der tonlosen Stimme draußen, die es sich selbst verbietet, lauter oder leiser zu werden, tritt drinnen die aufund abschwellende Musik Beethovens gegenüber. Ein voll konturiertes Außen ermöglicht, was bei Beckett sonst nicht zu hören ist: Die Inbrunst und Innerlichkeit romantischer Musik. Freilich ist deren Hörer kaum weniger verschlossen als das Außen im Endspiel. Die Figur umklammert einen Kassettenrekorder und bildet mit diesem - vom Zuschauer aus gesehen - eine akusmatische Einheit.

"Es ist, als ob man gleichzeitig ein Hörspiel und einen Stummfilm vorführte [...].॥ ${ }^{56}$ Diese präzise Formel Deleuzes deutet darauf hin, dass Geister-Trio, gemessen an He, Joe, weitere mediale Kopplungs- und Entkopplungseffekte ins Spiel bringt. Während die Stimme in $\mathrm{He}$, Joe Joe noch vom Außen her anspricht, während sie ihn bedrängt, während sie noch eine durchaus dramatische, da konfrontative Regie aus dem Off eröffnet, besitzt die Stimme in GeisterTrio trotz imperativischer Anklänge aufgrund ihrer Tonlosigkeit ein nachgerade kommentarhaftes Gepräge. Befiehlt sie oder sagt sie nicht vielmehr in redundanter Weise den nächsten vorhersehbaren Zug an, der den Regeln dieses Raumspiels entspricht? Dieser nichtdramatische, und das heißt: raumspielhafte Charakter verdankt sich einem gegenüber $H e$, Joe gegenläufigen Kopplungseffekt.

55 Ebd., S. 266.

56 Mit dieser Formel beschreibt Deleuze das Geister-Trio; vgl. G. Deleuze: »Erschöpft« (wie Anm. 29), S. 29. 
Geister-Trio entkoppelt die Beziehung von akusmatischer Stimme und Bühnenfigur und verkoppelt die Stimme mit dem Raum, den sie beschreibt, und den Aktionen der Figur, die sie nicht mehr anspricht, sondern bloß noch bespricht.

Solche Entkopplungen sind bei Beckett, dies deutet sich bereits in Film an, kein bloßes Regiemittel, sie entkoppeln zugleich gängige Wahrnehmungs- und Begriffszuordnungen. Verbreiteter Weise assoziiert man die Stimme mit Präsenz, Geist und Sinn und stellt ihr die Schrift als das Räumliche und Äußerliche gegenüber. Anders ist die Beckett'sche Stimme verfasst. Sie zeigt, dass die präsente Stimme unbeschadet ihrer Anwesenheit - auch außen sein kann. Auch so lässt sich Sinn dekonstruieren: Nicht indem man Präsenz gegen Absenz - so operiert noch Warten auf Godot - oder Stimme gegen Schrift - so argumentiert bekanntlich Derrida - ausspielt, sondern indem man die Stimme ins Außen setzt und zum Sprecher des Außen macht. Der philosophische Charakter Beckett'scher Raumspiele besteht mit darin, vertraute Spielanordnungen zu verändern. In zunehmendem Maße geht Beckett dazu über, nicht länger Philosophie zu persiflieren oder zu inszenieren, sondern statt ihrer andere Spiele zu erfinden. Man mag oder muss hinzusetzen, dass diese Spiel- und Raumanordnungen sich in verwandter Weise bei Lacan finden. Er führte gegenüber Freud zwei Neuerungen ein: Die Äußerlichkeit der Stimme und die des Auges. Von der Äußerlichkeit des Auges handelt Film. Von der Äußerlichkeit der Stimme in zunehmendem Maße der späte Beckett. 